\title{
Diverse Responses of Winter Wheat Yield and Water Use to Climate Change and Variability on the Semiarid Loess Plateau in China
}

\author{
Liang He, James Cleverly, Chao Chen, Xiaoya Yang, Jun Li, Wenzhao Liu, and Qiang Yu*
}

\begin{abstract}
Crop production and water use in rainfed cropland are vulnerable to climate change. This study was to quantify diverse responses of winter wheat (Triticum aestivum $\mathrm{L}$.) yield and water use to climate change on the Loess Plateau (LP) under different combinations of climatic variables. The crop model APSIM was validated against field experimental data and applied to calculate yield and water use at 18 sites on the LP during 1961 to 2010. The coefficient of variation of yield ranged from 12 to $66 \%$, in which the vulnerability of yield increased from the southeast (12\%) to the northwest (66\%). This change was attributed to the gradual increase in precipitation variation from the southeast to the northwest. An obvious warming trend during 1961 to 2010 resulted in a significant decrease in the growth duration by 1 to $5 \mathrm{~d} \mathrm{decade}^{-1}$. The yield at 12 sites was significantly reduced by 120 to $720 \mathrm{~kg} \mathrm{ha}^{-1} \mathrm{decade}^{-1}$. Evapotranspiration was significantly decreased by 1 to $26 \mathrm{~mm}$ decade $^{-1}$; however, water use efficiency at most sites showed no significant trend. Eighteen sites were classified into three climatic zones by cluster analysis: high temperature-high precipitation-low radiation (HHL), medium temperature-medium precipitation-medium radiation (MMM), and low temperature-low precipitation-high radiation (LLH). The trend of decreasing yield was smallest in the HHL cluster because of a minimal reduction in precipitation, while decreasing trends in yield and evapotranspiration were larger in the LLH and MMM because of larger reductions in precipitation. The results imply that among strategies such as breeding for long duration or drought tolerance, modification of the planting date will be necessary to avoid high temperatures associated with climate change.
\end{abstract}

Climatic factors such as solar radiation, precipitation, and temperature are major determinants of crop production and water use. Climate change is characterized by increased surface temperature and modified precipitation patterns (Intergovernmental Panel on Climate Change, 2007). Thus, crop production and water use are influenced by climate change. Consequently, a better understanding of the interactions between climatic factors and their impacts on crop production is essential for optimizing crop management, improving water use efficiency, and adopting reasonable strategies to mitigate climate change (Yu et al., 2014).

The Loess Plateau (LP, Fig. 1) is located in northern China, where dryland agriculture is the primary economic activity. The

L. He and J. Li, Key Lab. of Water Cycle and Related Land Surface Processes, Institute of Geographic Sciences and Natural Resources Research, Univ. of Chinese Academy of Science, Beijing 100049, China; J. Cleverly, C. Chen, and Q. Yu, Plant Functional Biology and Climate Change Cluster, Univ. of Technology Sydney, PO Box 123, Ultimo, NSW 2007, Australia; X. Yang, College of Applied Meteorology, Nanjing Univ. of Information Science and Technology, Nanjing, Jiangsu 210044, China; and W. Liu, State Key Lab. of Soil Erosion and Dryland Farming on the Loess Plateau, Institute of Soil and Water Conservation, Chinese Academy of Sciences and Ministry of Water Resources, Yangling, Shaanxi 712100, China. Received 2 July 2013. *Corresponding author (Qiang.Yu@uts.edu.au).

Published in Agron. J. 106:1169-1178 (2014)

doi:10.2134/agronj13.0321

Available freely online through the author-supported open access option. Copyright $(92014$ by the American Society of Agronomy, 5585 Guilford Road, Madison, WI 53711. All rights reserved. No part of this periodical may be reproduced or transmitted in any form or by any means, electronic or mechanical, including photocopying, recording, or any information storage and retrieval system, without permission in writing from the publisher.
LP has a typical continental monsoon climate, which means that it is cold in the winter and warm and humid in the summer. The average temperature ranges from $3.6^{\circ} \mathrm{C}$ in the north to $14.3^{\circ} \mathrm{C}$ in the south (Sun et al., 2010). Agriculture on the LP is vulnerable to climate change because the LP is situated in a semiarid region with low and variable rainfall. Within the LP, precipitation decreases gradually from 600 to $700 \mathrm{~mm}$ in the southeast to 100 to $150 \mathrm{~mm}$ in the northwest. More than $78 \%$ of the precipitation on the LP occurs between May and October. Interannual variation of precipitation is large, such that rainfall in wet years is two to five times higher than in dry ones. During the last few decades, notable climate change has been observed on the LP. The air temperature has substantially increased by $0.6^{\circ} \mathrm{C}$ decade $^{-1}$, while annual precipitation has insignificantly decreased by $3 \mathrm{~mm}$ decade $^{-1}$, although the interannual variability of temperature and rainfall is larger than the trends (Li et al., 2008, 2011; Piao et al., 2010; Turner et al., 2011; Wang et al., 2012; Xin et al., 2011). Additionally, extreme events like drought have become more frequent across the LP (Piao et al., 2010; Turner et al., 2011; Wang et al., 2012). A better understanding of how crop yield and water use respond to climate change and variability may offer insights that promote sustainable agriculture on the LP.

Abbreviations: ET, evapotranspiration; HHL, high temperature-high precipitation-low radiation cluster; LAI, leaf area index; LLH, low temperature-low precipitation-high radiation cluster; LP, Loess Plateau; MMM, medium temperature-medium precipitation-medium radiation cluster. 


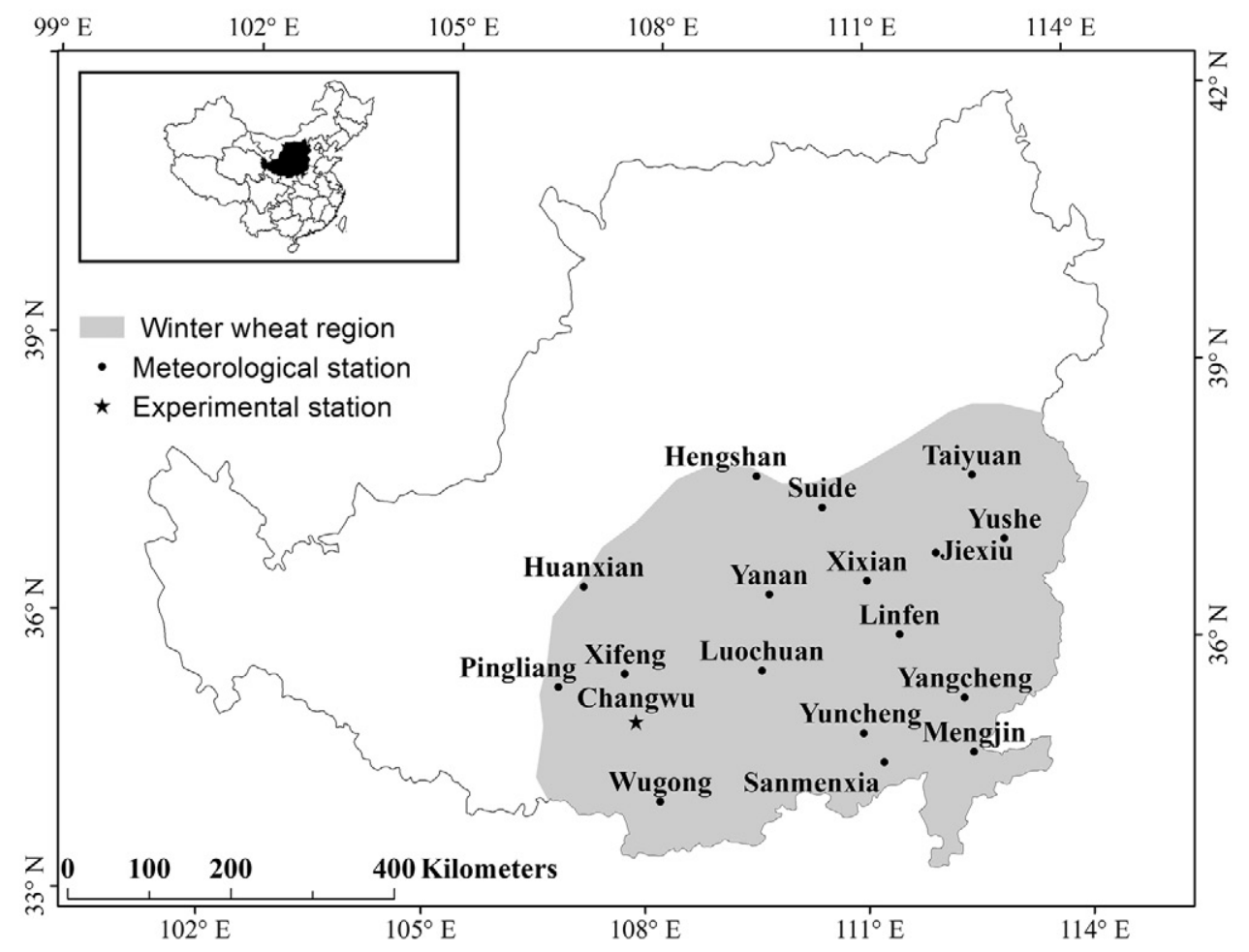

Fig. I. The Loess Plateau, distribution of winter wheat, and location of the Changwu agroecological experimental station.

Previous studies within the LP and northern China have focused on the site-specific impacts of climate change on crop yield and water use. Wang et al. (2008) investigated the relationship between temperature and winter wheat yield and found that increasing maximum temperature during the reproductive period negatively affected grain yield at Xifeng station on the LP from 1981 to 2004. Li et al. (2011) reported that grain yield in wheat and maize (Zea mays L.) would respond to changes in precipitation at two sites on the LP during 2010 to 2039. In contrast, Chen et al. (2010c, 2012) identified a multidecadal declining trend in solar radiation that was responsible for reduced yield and evapotranspiration in the North China Plain. Regional gradients in annual precipitation and spatial heterogeneity of climate and soil may restrict widespread applicability of these local studies across the LP. Therefore, quantification of regional responses of crop yield and water use to climate change would contribute to improved management practices for responding to climate change.

Two types of models are typically used to investigate crop responses to climate variation: statistical models and processbased models. Statistical models (e.g., regression models) are useful and simple (Lobell and Asner, 2003; Nicholls, 1997; Peng et al., 2004; Yu et al., 2001). However, the utility of statistical approaches depends on the availability of long-term measurements and is limited by the arbitrary selection of independent variables (Lobell and Burke, 2010). To overcome the limitations of statistical models, process-based crop models are validated against local experimental data and thus can be used to identify functional relationships between crop yield and meteorological forcing. Agricultural scientists commonly use this modeling approach to study the response of agricultural systems to climate change and management scenarios (Asseng et al., 1998a; Chen et al., 2010b; Yang et al., 2011; Yu et al., 2006).
APSIM is one such process-based model that has been widely used to simulate crop production and water use around the world (Asseng et al., 1998a, 1998b, 2011; Chen et al., 2010b; Probert et al., 1995; Reyenga et al., 2001; Wang et al., 2004; Yang et al., 2011), in the North China Plain (Chen et al., 2012, 2010a, 2010b, 2010c; Liu et al., 2010), and in Xinjiang autonomous region (Yang et al., 2011). We conducted a regional study of climate, crop yield, and evapotranspiration across the LP. The objectives of this study were: (i) to calibrate and validate the performance of the APSIM model for simulating the growth and water use of winter wheat on the LP, (ii) to simulate the impacts of past climate change and variability on crop production and water use using the validated APSIM model, and (iii) to investigate the responses of winter wheat yield and water use to climate change across gradients of rainfall and temperature on the LP. The balance of crop yield vs. water use was evaluated through estimates of plant water use efficiency.

\section{MATERIALS AND METHODS}

\section{Study Sites and Field Experiment}

The LP covers an area of 0.65 million $\mathrm{km}^{2}$, which is $6.76 \%$ of the total national land area of China (Wang and $\mathrm{Li}, 2010$ ). By 2008, the population of the LP had reached 108 million, with $70 \%$ of the population living and working in agricultural areas. The main crops are spring and winter wheat, maize, potato (Solanum tuberosum L.), proso millet (Panicum miliaceum L. ssp. miliaceum), foxtail millet [Setaria italica (L.) P. Beauv. ssp. italic], and pea (Pisum sativum L.), with smaller areas of buckwheat (Fagopyrum esculentum Moench), canola (Brassica napus L. ssp. napus) and faba bean (Vicia faba L.) (Deng et al., 2006; Turner et al., 2011). Wheat is the dominant crop on the LP and the planting area is about 5 million ha, 
Table I. Derived cultivar parameters for winter wheat at Changwu (Changwu89134).

\begin{tabular}{|c|c|}
\hline Parameter & Changwu89134 \\
\hline Vern_senst & 2.0 \\
\hline Photop_sens $\neq$ & 3.0 \\
\hline grains_per_gram_stem $\oint$,grains $g^{-1}$ stem & 25 \\
\hline Startgf_to_mat $\mathbb{\|},{ }^{\circ} \mathrm{C} d$ & 650 \\
\hline potential_grain_filling_rate\#,g kernel ${ }^{-1} \mathrm{~d}^{-1}$ & 0.0025 \\
\hline \multicolumn{2}{|l|}{$\dagger$ Sensitivity to vernalization. } \\
\hline \multicolumn{2}{|l|}{$\ddagger$ Sensitivity to photoperiod. } \\
\hline \multicolumn{2}{|c|}{$\S$ Coefficient of kernel number per stem weight at the beginning of grain filling. } \\
\hline \multicolumn{2}{|c|}{ \ Thermal time from beginning of grain filling to maturity. } \\
\hline \# Potential grain-filling rate. & \\
\hline
\end{tabular}

with production accounting for $10 \%$ of the national total (Turner et al., 2011; Wang and Li, 2010). Cropping is rainfall dependent on the LP for lack of available irrigation sources, thus the sustainability of agriculture in this semiarid region is strongly dependent on change and variability in rainfall.

Eighteen sites (Fig. 1), mainly distributed across the southeastern and central LP, were selected to cover the region of winter wheat production and were colocated with locations with available long-term daily records of maximum and minimum temperature, precipitation, and sunshine hours. The field experiment was located at Changwu agroecological experimental station $\left(107.8^{\circ} \mathrm{E}, 35.2^{\circ} \mathrm{N}\right)$, which is located in Shaanxi province in the south-central part of the LP (Fig. 1). Mean annual precipitation at Changwu is $578.5 \mathrm{~mm}$, mean annual air temperature is $9.1^{\circ} \mathrm{C}$, and the annual frost-free period is $171 \mathrm{~d}$. The soil texture is predominantly a silty clay loam (Wang et al., 2011). Data from the field experiment were used to calibrate and validate the APSIM model.

Measurements at Changwu during the 2005-2006 and 2007-2008 growth seasons included evapotranspiration (ET), phenological stage, leaf area index (LAI), biomass, and grain yield. A weighing lysimeter $\left(3 \mathrm{~m}^{2}\right)$ was installed to a depth of $3 \mathrm{~m}$ for measuring ET. Soil water content was measured every $10 \mathrm{~cm}$ from the 10 - to $100-\mathrm{cm}$ depth on one out of every $5 \mathrm{~d}$ using a neutron probe. Before sowing, $300 \mathrm{~kg} \mathrm{ha}^{-1}$ urea and $700 \mathrm{~kg} \mathrm{ha}^{-1}$ superphosphate were applied. No irrigation was used during the entire experiment period.

\section{The APSIM Model}

The Agricultural Production Systems Simulator (APSIM) is a modular modeling framework that has been developed by the Agricultural Production Systems Research Unit in Australia (Keating et al., 2003; McCown et al., 1996). Simulation modules include crop growth and development, soil water, soil $\mathrm{N}$, and crop management, which allow flexible simulations of management options such as rotation type, fertilization, and irrigation. The APSIM model Version 7.4 was used to simulate the phenological development, biomass growth, grain yield, and water balance of winter wheat in a rainfed cropping system. The built-in modules used in this study were wheat crop (WHEAT), soil water (SOILWAT2), soil N (SOILN2), crop residue (RESIDUE), and management specification (MANAGER). Detailed descriptions of each module can be found at the APSIM website (www.apsim.info).

APSIM runs at a daily time step using daily meteorological and soil data. The meteorological data include maximum and minimum temperatures, rainfall, and sunshine duration. Historical data from 18 weather stations (Fig. 1) were available for the period 1961 to 2010 from the China Meteorological Administration (http://cdc.cma.gov.cn/). Sunshine duration was converted into solar radiation by using the Ångström-Prescott equation (Prescott, 1940). Cultivar-specific sensitivity parameters for winter wheat at Changwu station are shown in Table 1. The other crop parameters were kept unchanged from APSIM Version 7.4. Soil data that are required by APSIM include soil physical characteristics (texture and bulk density), organic $\mathrm{C}$ concentration, and soil hydraulic characteristics (saturation, field capacity, and lower limit) in different layers. These data were obtained from field experiments and the soil database of China (www.soil.csdb.cn). The soil data for Changwu used in APSIM are shown in Table 2 and also can be found in Zhang and Liu (2005).

\section{Data Analysis}

The performance of the model was evaluated using the slope, coefficient of determination $\left(R^{2}\right)$ of the regression lines, and an index of agreement $(d)$ (Willmott et al., 1985) between simulated and measured values. The temporal trends in simulated yield, water use, and the corresponding meteorological variables (rainfall, temperature, and solar radiation) during the growing season (September-July) were determined by linear regression: $y=k x+b$,

Table 2. Soil properties of experimental sites at Changwu at depths of 0 to $180 \mathrm{~cm}$. All soils had a silty clay loam texture.

\begin{tabular}{|c|c|c|c|c|c|c|}
\hline Property & $0-20 \mathrm{~cm}$ & $20-40 \mathrm{~cm}$ & $40-60 \mathrm{~cm}$ & $60-80 \mathrm{~cm}$ & $80-100 \mathrm{~cm}$ & $100-180 \mathrm{~cm}$ \\
\hline $\mathrm{BD}, \mathrm{g} \mathrm{cm}^{-3}$ & 1.41 & 1.41 & 1.38 & 1.31 & 1.26 & 1.40 \\
\hline SAT, $\mathrm{mm} \mathrm{mm}^{-1}$ & 0.425 & 0.404 & 0.392 & 0.452 & 0.455 & 0.432 \\
\hline $\mathrm{DUL}, \mathrm{mm} \mathrm{mm^{-1 }}$ & 0.305 & 0.305 & 0.313 & 0.311 & 0.309 & 0.309 \\
\hline $\mathrm{LL}, \mathrm{mm} \mathrm{mm}{ }^{-1}$ & 0.094 & 0.094 & 0.115 & 0.110 & 0.106 & 0.106 \\
\hline
\end{tabular}

† BD, bulky density; SAT, saturation; DUL, drained upper limit or field capacity; LL, lower limit.

Table 3. Mean values of mean temperature (MeanT), maximum temperature (MaxT), minimum temperature (MinT), precipitation, and solar radiation during the growing season in three clusters.

\begin{tabular}{|c|c|c|c|c|c|c|}
\hline Cluster $\dagger$ & Locations & MeanT & MaxT & MinT & Precipitation & Radiation \\
\hline & no. & 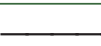 & $-{ }^{\circ} \mathrm{C}-$ & 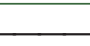 & $\mathrm{mm}$ & MJ $\mathrm{m}^{-2}$ \\
\hline $\mathrm{HHL}$ & 7 & 11.7 & 17.1 & 6.4 & 479.8 & 4420.1 \\
\hline MMM & 7 & 9.5 & 15.4 & 3.4 & 403.1 & 4585.4 \\
\hline LLH & 4 & 8.8 & 15.2 & 2.4 & 320.8 & 4744.5 \\
\hline
\end{tabular}

† HHL, high temperature-high precipitation-low radiation; MMM, medium temperature-medium precipitation- medium radiation; LLH, low temperature-low precipitation-high radiation. 


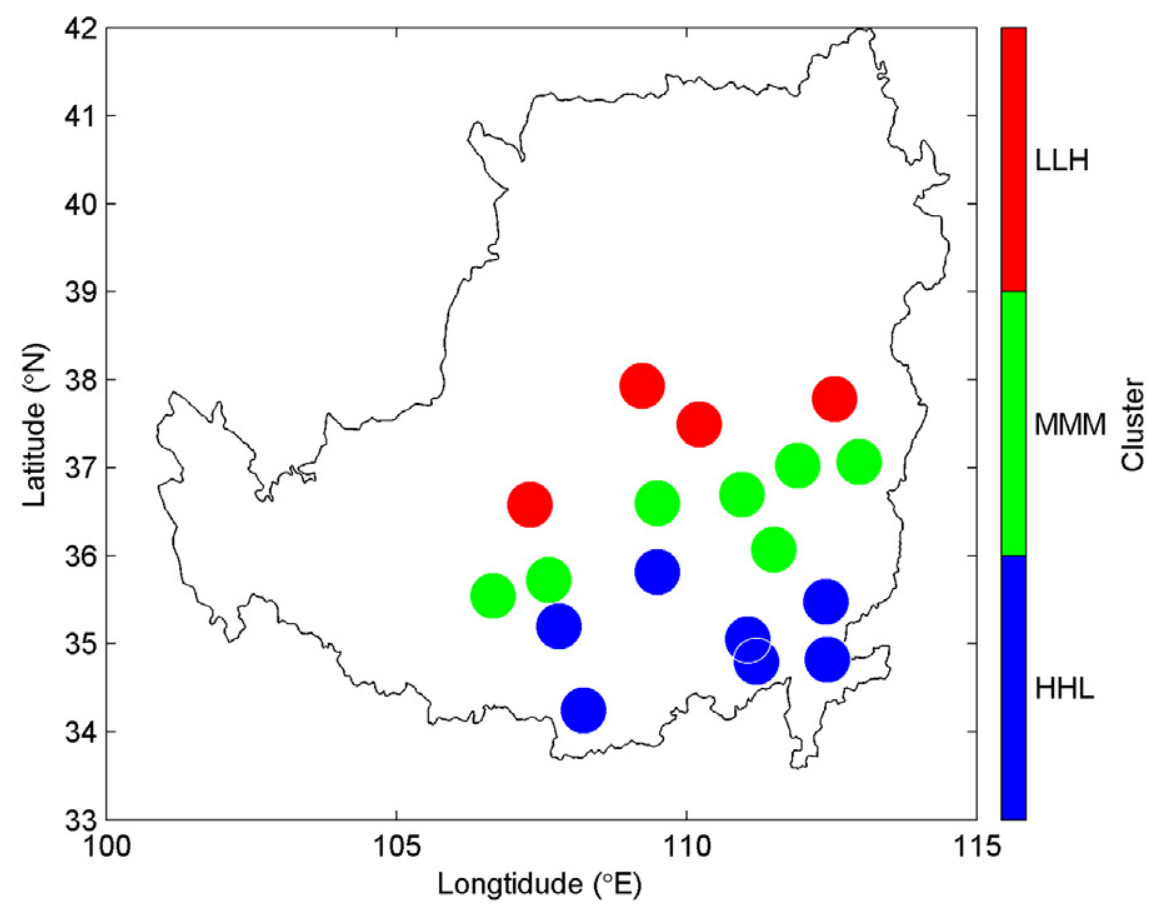

Fig. 2. Spatial distribution of the three climate clusters: high temperature-high precipitation-low solar radiation pattern (HHL); medium temperaturemedium precipitation-medium solar radiation pattern (MMM); and low temperature-low precipitation-high solar radiation pattern (LLH).
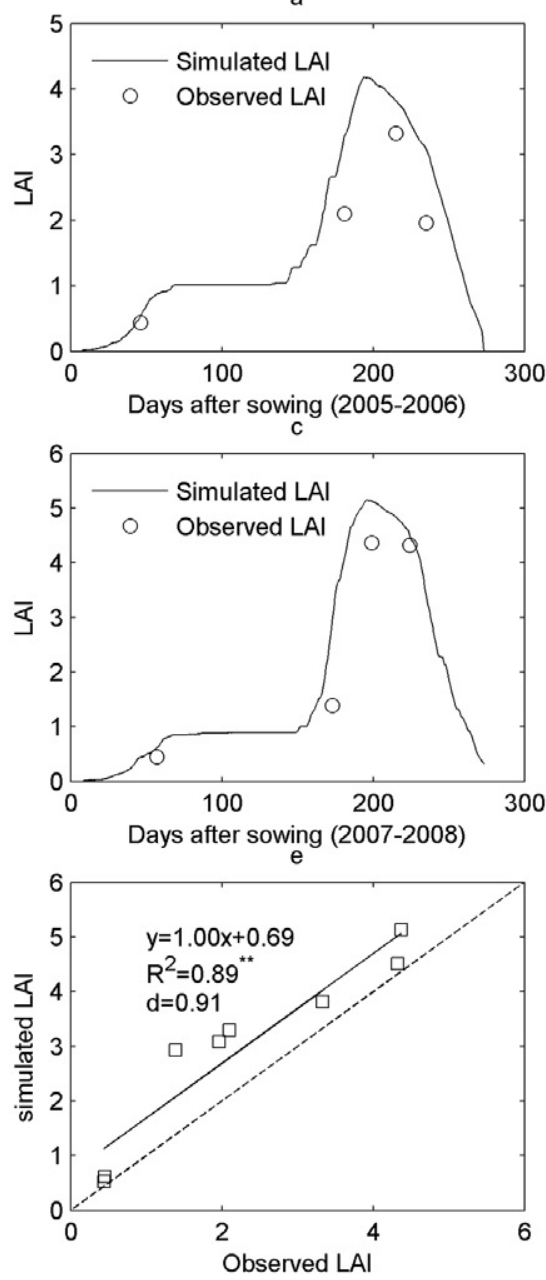
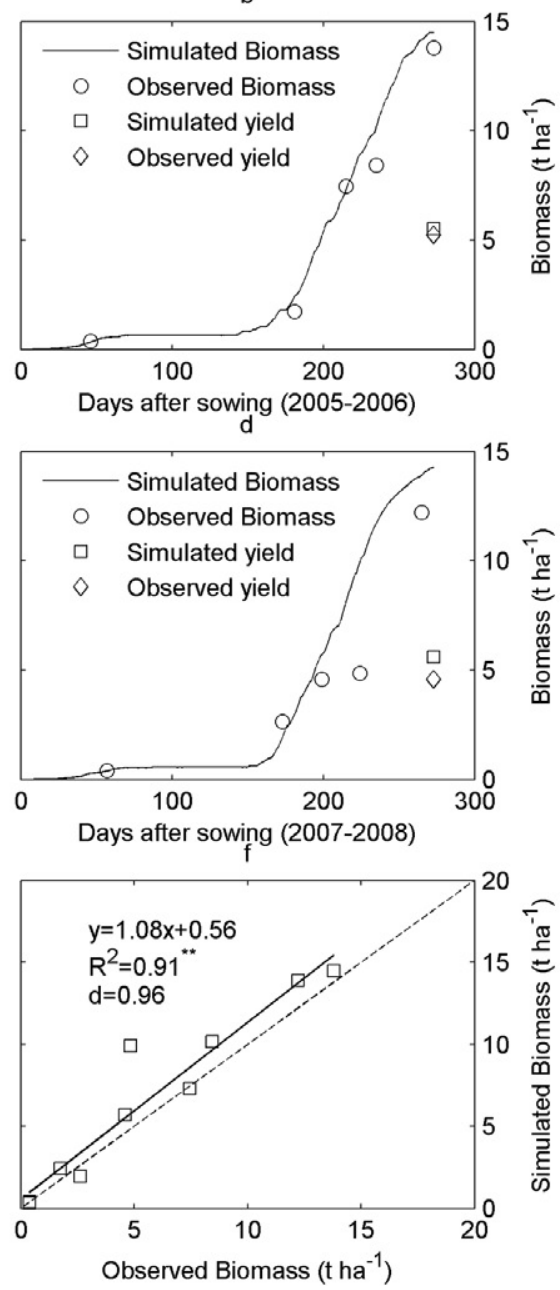

Fig. 3. Comparison of observed and simulated leaf area index (LAI) and aboveground biomass and yield at Changwu station: (a,b) experimental data from 2005 to 2006 used to calibrate the APSIM; and (c,d) experimental data from 2007 to 2008 used to validate APSIM. **Statistically significant at $p=0.01$. 

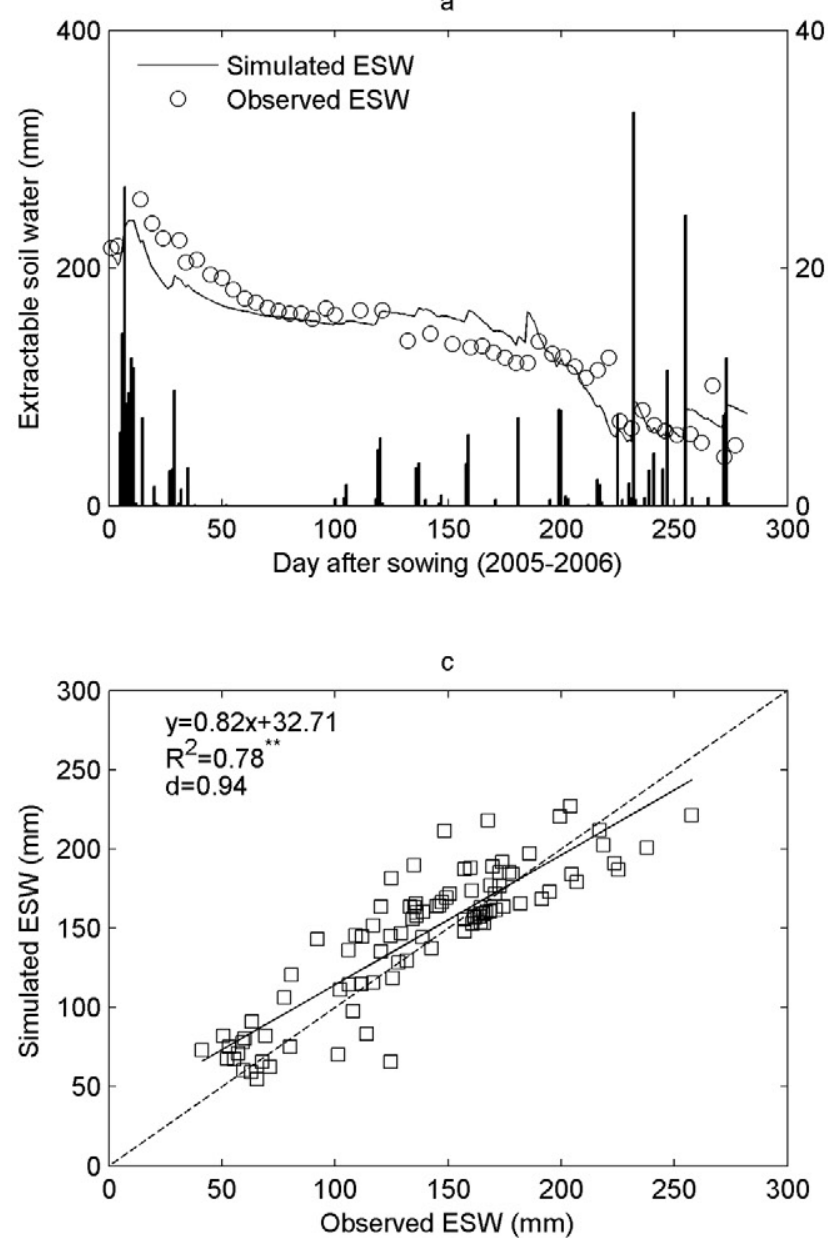

b

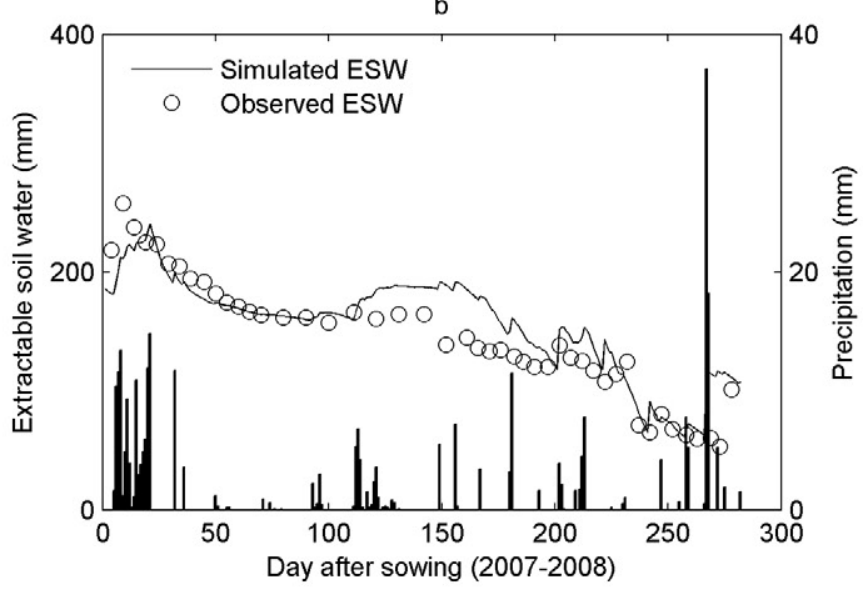

d

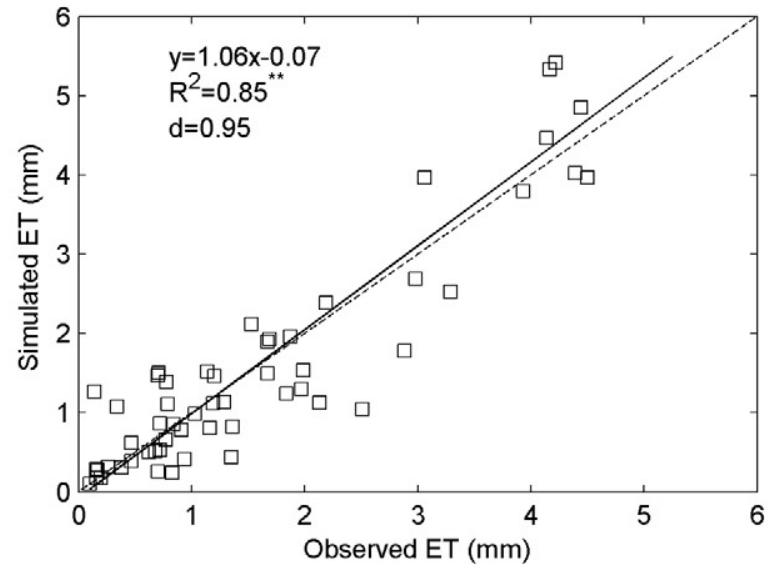

Fig. 4. (a,b,c) Comparison of simulated and observed extractable soil water (ESW) at a depth of $100 \mathrm{~cm}$ and (d) 10 - $d$ total lysimetric evapotranspiration (ET) in the winter growing seasons (2005-2006 and 2007-2008) at Changwu. **Statistically significant at $p=0.0 \mathrm{I}$.

where $y$ is the simulated yield, water use, or corresponding meteorological variable, $k$ is the slope, $b$ is the intercept, and $x$ is the year. A two-tailed $t$-test was conducted to determine whether the slope of the regression line was significant.

\section{Climate Zones}

Cluster analysis was applied to classify the 18 sites across the LP into groups of similar climatic patterns. Daily temperature (mean, maximum, and minimum), precipitation, and solar radiation during the winter wheat growing season (SeptemberJuly) were the clustering variables in the analysis. The $k$-means method of clustering (Seber, 2008) was adopted using MATLAB (MATLAB 2012a, The MathWorks).

The 18 sites were clustered into three climate zones (Table 3 ), which were roughly distributed along a north-south axis (Fig. 2). Zone HHL (high temperature-high precipitationlow radiation) had the highest temperature $\left(11.7^{\circ} \mathrm{C}\right.$, Table 3$)$, highest precipitation ( $479.8 \mathrm{~mm}$, Table 3$)$, and lowest solar radiation (4420.1 $\mathrm{MJ} \mathrm{m}^{-2}$, Table 3). Conversely, sites in Zone LLH (low temperature-low precipitation-high radiation) were characterized by the lowest temperature $\left(8.8^{\circ} \mathrm{C}\right.$, Table 3), lowest precipitation (320.8 mm, Table 3), and highest solar radiation (4744.5 $\mathrm{MJ} \mathrm{m}^{-2}$, Table 3). Accordingly, Zone MMM was an intermediate cluster characterized by intermediate temperature, precipitation, and radiation (Table 3 ).

\section{RESULTS}

\section{Model Calibration and Validation}

Figure 3 shows a comparison between simulated and observed LAI, aboveground biomass, and grain yield during the 2005-2006 and 2007-2008 growing seasons. Simulated LAI and aboveground biomass agreed well with observed values during both growing seasons (slope 1.00-1.08, $R^{2} \geq 0.80, p<0.01, d \geq 0.90$; Fig. 3e-3f). Figure 4 a to $4 \mathrm{c}$ show comparisons between the simulated and observed extractable soil water at Changwu station at the $100-\mathrm{cm}$ depth (slope $=0.82, R^{2}=0.78, p<0.01, d=0.94$ ). Figure $4 \mathrm{~d}$ shows a comparison between the simulated and observed ET at Changwu station (slope $=1.06, R^{2}=0.85, p<0.01, d=$ $0.95)$. Based on the slopes that were near $1(0.8-1.1)$, large $R^{2}$ (0.78-0.85), and larger agreement index $d(0.90-0.95)$, the performance of the model was considered to be satisfactory for the simulation of wheat growth and water use across the LP.

\section{Spatial and Temporal Trends in Climate Change, Crop Phenology, Yield, and Water Use}

Figure 5 shows the spatial pattern of climate trends (1961-2010) during the growing season. Growing season mean temperature increased by 0.1 to $0.6^{\circ} \mathrm{C}$ decade $^{-1}$ across the LP, with larger increases in maximum $\left(0.8^{\circ} \mathrm{C}\right.$ decade $\left.^{-1}\right)$ and minimum $\left(0.7^{\circ} \mathrm{C} \mathrm{decade}{ }^{-1}\right)$ temperatures (Fig. 5a-5c). 

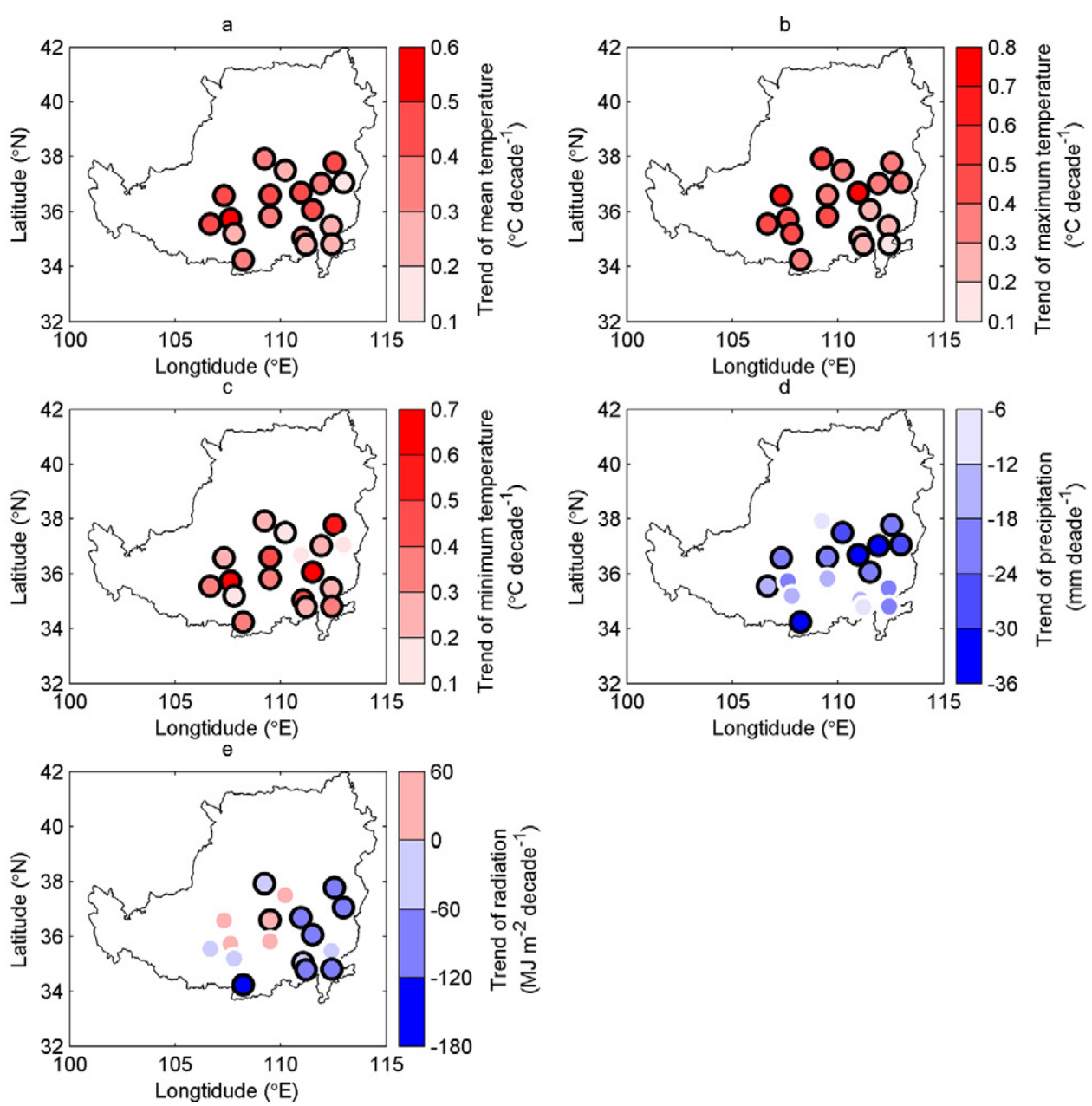

Fig. 5. Spatial patterns of the climatic trends in (a) mean temperature, (b) mean maximum temperature, (c) mean minimum temperature, (d) precipitation, and (e) solar radiation during the growing season (September-July) from I96I to 20I0. Black-edged circles indicate statistical significance at $p=0.05$.

Precipitation significantly decreased by 6 to $36 \mathrm{~mm} \mathrm{decade}^{-1}$ at 10 sites across the LP (Fig. 5d). Solar radiation declined by 60 to $180 \mathrm{MJ} \mathrm{m}^{-2}$ decade $^{-1}$ across the eastern and southern boundary of the LP (Fig. 5e). In contrast, solar radiation increased significantly $\left(56 \mathrm{MJ} \mathrm{m}^{-2}\right.$ decade $\left.^{-1}\right)$ at one of the interior sites (Yanan, Fig. 5e).

The mean and coefficient of variation $(\mathrm{CV})$ of simulated winter wheat yield and precipitation during the growing season (1961-2010) at 18 sites are shown in Fig. 6. Mean simulated wheat yield (the black circles in Fig. 6) declined from $5134 \mathrm{~kg}$ $\mathrm{ha}^{-1}$ at the southeastern-most site (Mengjin) to $1941 \mathrm{~kg} \mathrm{ha}^{-1}$ at northwestern-most site (Hengshan). Rainfall (the black squares in Fig. 6) declined from 523 to $273 \mathrm{~mm}$ (Fig. 6). Annual CV was 12 to $66 \%$ for yield and 19 to $32 \%$ for precipitation, both of which increased with declining mean values (Fig. 6).

Long-term trends in phenology (growth duration), yield, and water use are shown in Fig. 7. The length of the growing season has significantly decreased by 1 to $5 \mathrm{~d} \mathrm{decade}^{-1}(p<0.05)$ across the LP (Fig. 7a). The increasing temperature resulted in a decreasing growth duration. Thus, the spatial pattern of the trend in growth duration (Fig. 7a) was similar to the pattern of the trend in mean temperature (Fig. 5a). Simulated grain yield was significantly reduced at 12 locations during the past $50 \mathrm{yr}$, declining by 120 to $720 \mathrm{~kg} \mathrm{ha}^{-1}$ decade $^{-1}$ (Fig. 7b).

Simulated ET declined by 1 to $26 \mathrm{~mm} \mathrm{decade}^{-1}(p<0.05)$, with significant reductions in ET identified at two-thirds of the sites (Fig. 7c). Simulated water use efficiency (yield/ET) declined significantly by 0.3 to $1.5 \mathrm{~kg} \mathrm{ha}^{-1} \mathrm{~mm}^{-1} \mathrm{decade}^{-1}$ at seven locations (Fig. 7d).

\section{Climate Zones and Correlation with Mean Yield, Evapotranspiration, Phenology, and Water Use Efficiency}

Yield and ET were significantly larger in the southern climate zone HHL (5106 $\mathrm{kg} \mathrm{ha}^{-1}$ and $371.9 \mathrm{~mm}$, respectively, Table 4) and smaller in the northern climate zone LLH (2796 $\mathrm{kg} \mathrm{ha}^{-1}$ and $275.7 \mathrm{~mm}$, respectively, Table 4). The CV in yield was largest in the north $(61.9 \%$, Table 4$)$ and smallest in the south (17.9\%, Table 4). Yield, CV of yield, and ET were intermediate in the central climate zone MMM (Table 4). The gradient of climatic factors from southeast to northwest on the LP (cf. Table 3 and Fig. 2) was the primary determinant of yield.

Yield $(r=0.83, p<0.01)$ and ET $(r=0.78, p<0.01)$ were positively and significantly correlated with precipitation (Table 5). Growth duration was negatively related with temperature and positively related with total solar radiation during the growing season. Water use efficiency was positively related to precipitation $(r=0.88, p<0.01)$ and minimum temperature $(r=0.50, p<0.01$, Table 5). 


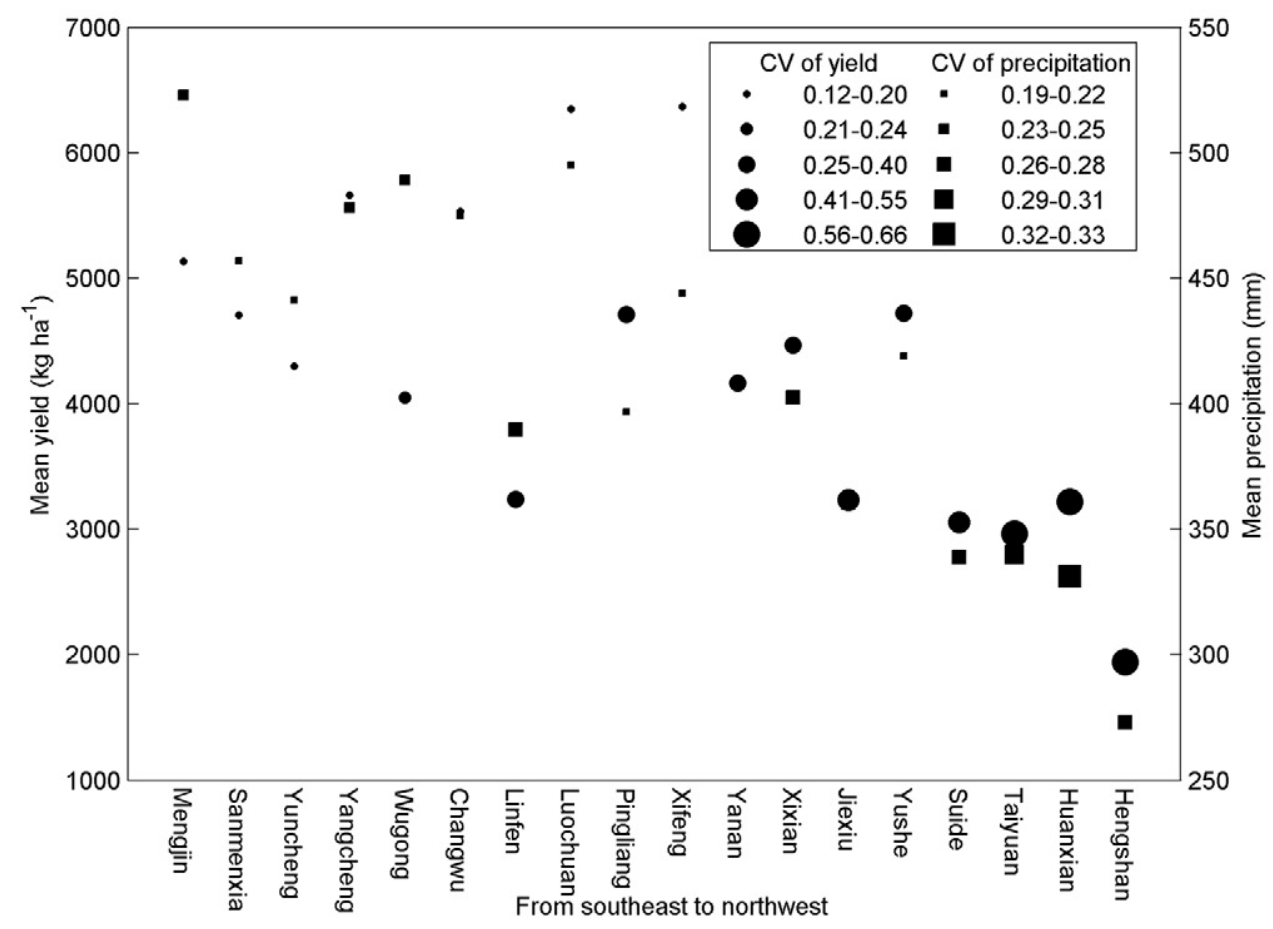

Fig. 6. Coefficient of variation and mean of simulated yield and precipitation for wheat growing seasons from $196 \mathrm{I}$ to 2010.
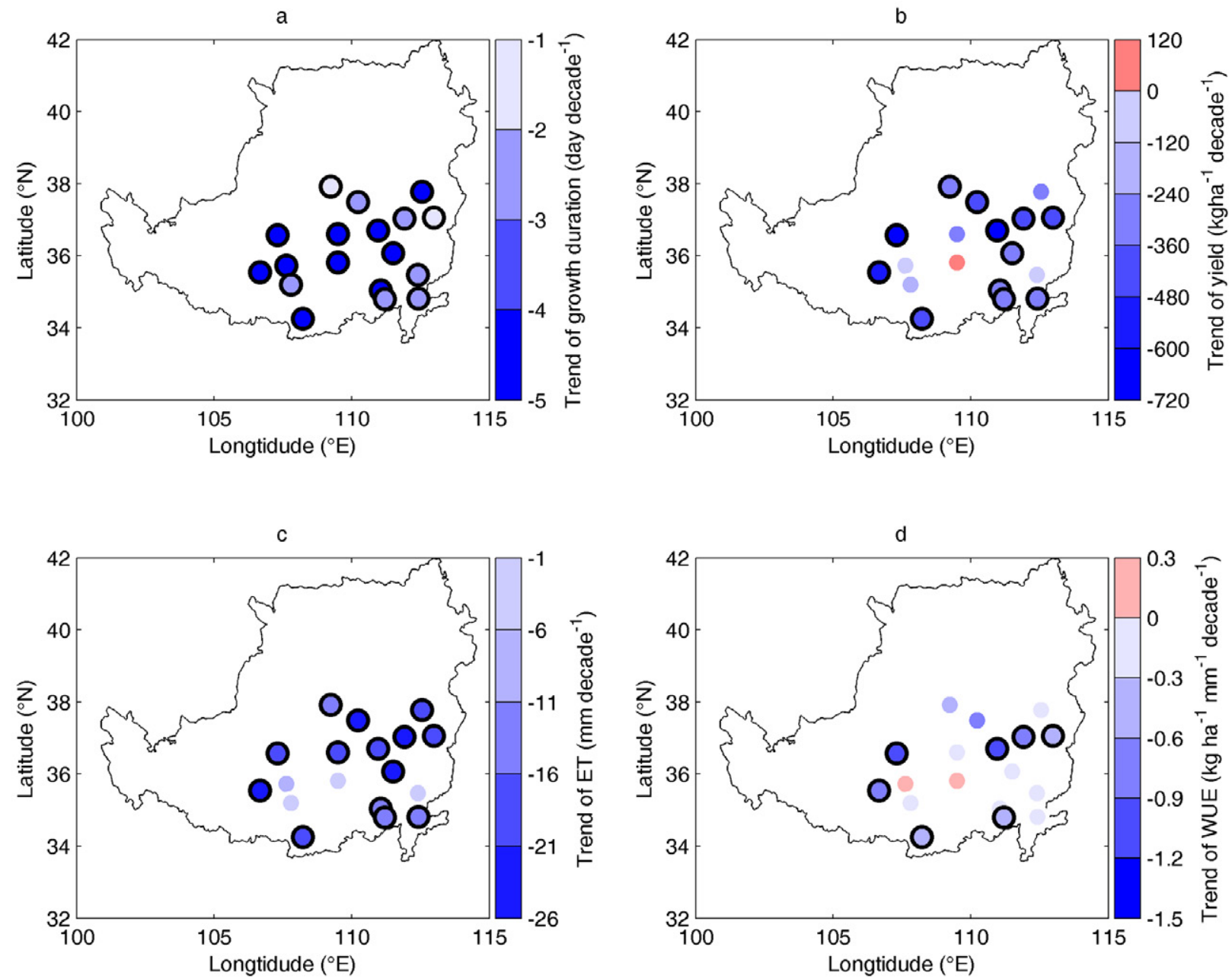

Fig. 7. Trends in simulated (a) wheat growth duration, (b) grain yield, (c) evapotranspiration (ET), and (d) water use efficiency (WUE) from I96I to 2010. Black-edged circles indicate statistical significance at $p=0.05$. 
Table 4. Mean values of wheat yield, evapotranspiration (ET), and coefficient of variation of yield $(\mathrm{CV})$ during the growing season in three clusters.

\begin{tabular}{lcccc}
\hline \multicolumn{1}{c}{ Clustert } & Locations & Yield & ET & CV \\
\hline & no. & $\mathrm{kg} / \mathrm{ha}$ & $\mathrm{mm}$ & $\%$ \\
$\mathrm{HHL}$ & 7 & 5106 & 371.9 & 17.9 \\
MMM & 7 & 4416 & 350.7 & 36.4 \\
LLH & 4 & 2796 & 275.7 & 61.9 \\
\hline
\end{tabular}

† HHL, high temperature-high precipitation-low radiation; MMM, medium temperature-medium precipitation-medium radiation; LLH, low temperature-low precipitation-high radiation.

\section{DISCUSSION}

\section{Historical Climate Change on the Loess Plateau}

The winter wheat region of the LP has become warmer $\left(0.1-0.7^{\circ} \mathrm{C} \mathrm{decade}^{-1}\right)$ in the past five decades, although significant reductions in precipitation were not widespread. Temperature increases were representative of the entire LP $\left(+0.4^{\circ} \mathrm{C}\right.$ decade $^{-1}$; Li et al., 2008; Wang et al., 2012) and comparable to but generally larger than globally averaged warming $\left(0.10-0.16^{\circ} \mathrm{C}\right.$ decade $^{-1}$; Intergovernmental Panel on Climate Change, 2007).

Most eastern sites showed significant decreases in solar radiation during the winter wheat growing seasons (Fig. 5e). The decrease in solar radiation might be attributed to an increase in anthropogenic aerosols, which is mainly caused by the emission of pollutants that modify the optical properties of the atmosphere and clouds in particular (Guan et al., 2011; Stanhill and Cohen, 2001).

\section{Responses of Crop Yield to Climate Variability}

Rainfed crop production is sensitive to variability in rainfall during the growing season. About $80 \%$ of world's cropland is rainfed and $>60 \%$ of world's cereal grains are produced without irrigation, thus placing a majority of the world's crop production at risk to variations in precipitation (Rockstrom et al., 2010). In other rainfed farming areas, the CV of wheat yield will reach 18 to $92 \%$ in Australia (Doherty et al., 2010) and 20 to $60 \%$ in sub-Saharan Africa (Cooper et al., 2008). The CV of wheat yield on the LP varied from 12 to $66 \%$, which is attributed to a gradual increase in precipitation that varied from the southeast to the northwest. The interannual variability of yield because of the large variability in precipitation on the LP is larger than the trends. For the rainfed agriculture the impact of climate variability on annual crops will be much higher than the trend of climate change (Yu et al., 2014).

\section{The Impact of Climate Change on Crop Phenology, Yield, and Water Use}

Meteorological and climatic factors play an important role in crop development and water use. The most relevant meteorological factor that limited yield $(r=0.83)$ and ET $(r=0.78)$ was precipitation during the growing season (Table $5)$. Reductions in water demand by winter wheat $(1-26 \mathrm{~mm}$ decade $^{-1}$ ) was similar to the reduction in ET that was reported for the North China Plain $\left(23 \mathrm{~mm}\right.$ decade $^{-1}$; Chen et al., $2010 \mathrm{~b})$ and in a groundwater-fed oasis cropland in Xinjiang (8 $\mathrm{mm} \mathrm{decade}^{-1}$; Yang et al., 2011), although declining ET in the latter case has been attributed to declining solar radiation
Table 5. Correlation coefficients for mean values of wheat yield, evapotranspiration (ET), growth duration (GD), and water use efficiency (WUE) with mean temperature (MeanT), maximum temperature (MaxT), minimum temperature (MinT), precipitation (Pre), and solar radiation ( $\mathrm{Rad}$ ) during the growing season on the Loess Plateau.

\begin{tabular}{lccccc}
\hline Parameter & Pre & MeanT & MaxT & MinT & Rad \\
\hline Yield & $0.83 * *$ & 0.04 & -0.20 & $0.23 *$ & -0.16 \\
ET & $0.78 * *$ & -0.10 & -0.30 & 0.06 & -0.14 \\
GD & -0.38 & $-0.98 * *$ & $-0.93 * *$ & $-0.92 * *$ & $0.60 *$ \\
WUE & $0.88 * *$ & 0.31 & 0.05 & $0.50 *$ & -0.29 \\
\hline
\end{tabular}

* Significant at the 0.05 probability level.

** Significant at the 0.01 probability level.

in contrast to the precipitation-driven results of this study. In this rainfed farming area, as in other unirrigated agricultural areas, rainfall was the predominant factor determining yield and soil evaporation (Rockstrom et al., 2010).

Warming temperatures explained the remainder of the variability in yield and phenology across the LP (Table 5). The small correlation between yield and minimum temperature $(r=0.23)$ was significantly different from zero (Table 5). Nocturnal warming reduces mortality due to cold or freezing stress (Nicholls, 1997), thereby improving survival rates during the overwintering period (Gholipoor, 2012; Wang et al., 2008). In contrast, a strong correlation with warming temperatures (Table 5) led to shortening of the growing season by 1 to $5 \mathrm{~d} \mathrm{decade}^{-1}$, which is consistent with warming-induced reductions in season length $\left(1.5-3 \mathrm{~d} \mathrm{decade}^{-1}\right)$ that were found in other studies (Chen et al., 2010b; Liu et al., 2010; Wang et al., 2008; Yang et al., 2011). In addition to advancing phenological dates, warming has led to shifts toward earlier timing of pseudo-stem elongation (13.2 d), booting (9.8 d), anthesis (11.0 d), and ripening (10.8 d) during 1983 to 2004 (Wang et al., 2008). Reductions in yield with climate change in our study were associated indirectly with growing season responses to increasing temperature in addition to the direct effects of precipitation on yield and ET.

The remaining meteorological factors (e.g., maximum temperature and solar radiation) were not significantly correlated with yield or ET (Table 5). Likewise, trends in yield at a subset of sites distributed across the LP were small and not significantly different from zero (Fig. 7b). Based on previous studies, larger responses in yield to changes in radiation were expected (Yang et al., 2011). However, the correlations between solar radiation and yield $(r=-0.16$, Table 5$)$ or ET $(r=-0.14$, Table 5) were not significantly different from zero in this rainfed agricultural region. Although trends in radiation at eastern sites across the LP were significant (Fig. 5e), the small decreases in solar radiation had little or no effect on yield and ET because radiation is not the limiting factor in arid areas (Stanhill and Cohen, 2001; Sun et al., 2010) such as the highradiation zone in the current study $\left(5500-6500 \mathrm{MJ} \mathrm{m}^{2} \mathrm{yr}^{-1}\right)$.

According to predictions from climate simulation models, mean temperatures on the LP will increase by 2.5 to $3.75^{\circ} \mathrm{C}$ by 2050. Rainfall is not expected to change, while the frequency of heat waves and dry spells are predicted to increase (Turner et al., 2011). Rising temperature will result in an acceleration of crop phenology and a reduction in crop yield as a consequence of the significant negative correlation between the growth duration and temperature. Additionally, rising temperatures 
Table 6. Mean trends in wheat yield, evapotranspiration (ET), mean temperature (MeanT), maximum temperature (MaxT), minimum temperature (MinT), precipitation, and solar radiation during the growing season in three clusters.

\begin{tabular}{|c|c|c|c|c|c|c|c|}
\hline Cluster $†$ & Yield & ET & MaxT & MinT & MeanT & Precipitation & Radiation \\
\hline & $\mathrm{kg} \mathrm{ha}^{-1}$ decade $^{-1}$ & $\mathrm{~mm} \mathrm{decade} \mathrm{e}^{-1}$ & 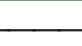 & $-{ }^{\circ} \mathrm{C}$ decade ${ }^{-1}$ & 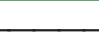 & $\mathrm{mm}$ decade ${ }^{-1}$ & $\mathrm{MJ} \mathrm{m^{-2 } \text { decade }}$ \\
\hline $\mathrm{HHL}$ & -198.2 & -10.5 & 0.30 & 0.31 & 0.30 & -18.2 & -52.5 \\
\hline MMM & -396.3 & -20.0 & 0.43 & 0.35 & 0.39 & -24.5 & -56.6 \\
\hline LLH & -417.0 & -18.9 & 0.46 & 0.30 & 0.38 & -20.2 & -21.5 \\
\hline
\end{tabular}

$\dagger \mathrm{HHL}$, high temperature-high precipitation-low radiation; MMM, medium temperature-medium precipitation-medium radiation; LLH, low temperature-low precipitation-high radiation.

and the increasing frequency of heat waves present a greater risk of crop failure during reproductive development. The predicted climate for the LP is a challenge for winter wheat production. The challenge for winter wheat production on the LP is that selection of long-duration and drought-resistant cultivars coselects for reduced yield under the predicted climate scenarios unless planting dates are shifted to an earlier time.

\section{Responses of Yield and Water Use in Different Climate Zones}

Responses of yield and water use within each cluster were different from the responses in the other climatic zones. The declining trend in yield within Zone HHL was smallest $\left(-198.2 \mathrm{~kg} \mathrm{ha}^{-1}\right.$ decade $^{-1}$, Table 6$)$ because of the smallest declines in precipitation $\left(-18.2 \mathrm{~mm} \mathrm{decade}^{-1}\right.$, Table 6$)$ and temperature $\left(0.30^{\circ} \mathrm{C}\right.$ decade $\left.^{-1}\right)$ within this zone. In Zones MMM and LLH, long-term reductions in yield were larger than in Zone HHL (-396.3 $\mathrm{kg} \mathrm{ha}^{-1}$ decade $^{-1}$ and $-417.0 \mathrm{~kg} \mathrm{ha}^{-1}$ decade $^{-1}$, respectively, Table 6) but not substantially different from each other. Similarly, trends in temperature at the stations in Zones MMM $\left(0.39^{\circ} \mathrm{C}\right.$ decade $\left.^{-1}\right)$ and LLH $\left(0.38^{\circ} \mathrm{C} \mathrm{decade}^{-1}\right)$ were not different from each other and were larger than in Zone HHL. In contrast, the largest reductions in ET were found in Zone MMM (-20.0 $\mathrm{mm} \mathrm{decade}^{-1}$, Table 6), where the largest reductions in precipitation $\left(-24.5 \mathrm{~mm} \mathrm{decade}^{-1}\right)$ occurred, which implies that the decline in ET correlated with the decline in precipitation. The results of this cluster analysis showed that the reductions in yield were associated with reductions in precipitation and increasing temperature, while reductions in ET were associated with declining precipitation.

The spatial heterogeneity of meteorological factors was probably the main reason for the diverse response. The spatial heterogeneity of meteorological factors contributed to diverse responses in crop production and water use, which was consistent with a study by Tao et al. (2006) that found climate change patterns and their impacts on crop phenology and yields to be spatially diverse across China. In their study, temperature was negatively correlated with crop yield at all stations except Harbin in northeastern China, where present temperatures were not above the optimal range for crop production. In our study, differences in climatic patterns among zones contributed to the diversity of trends in wheat production and water use. Local climate conditions were partially dictated by topography. For example, a previous study showed that enhancement in yield in Tongwei County of the LP was larger at high elevation (Xiao et al., 2010). The topographic relief across the LP causes spatial variability in the distribution of water and energy, which leads to the diverse responses of crop yield and ET that were found in our study.

\section{CONCLUSIONS}

Significant warming and drying were identified across the winter wheat region of the LP. Large interannual variation in precipitation was related to the variable responses of production of winter wheat and its agricultural vulnerability. The CV of yield was 12 to $66 \%$ and increased with a gradient of declining precipitation from southeast to northwest. The trend of yield at some sites was not significant because of the large interannual variation. The simulated length of the growing season decreased by $1-5 \mathrm{~d}_{\text {decade }}{ }^{-1}$ due to warming on the LP from 1961 to 2010. Likewise, reductions in yield were related to declining precipitation and increasing minimum (i.e., overnight) temperatures. Evapotranspiration significantly decreased by 1 to $26 \mathrm{~mm} \mathrm{decade}{ }^{-1}$, which was correlated with reductions in precipitation.

Three climatic patterns were identified by locations within the LP. The HHL pattern was defined by high temperature and precipitation coupled with low solar radiation. Because the mean temperature was smaller and solar radiation larger in the LLH and MMM clusters, reductions in yield and ET were larger in response to climate change in these clusters than in the HHL zone.

\section{ACKNOWLEDGMENTS}

This study was supported by National Basic Research Program of China (973 Program, no. 2012CB955304) and China National Science Foundation (no. 41171033).

\section{REFERENCES}

Asseng, S., I.R.P. Fillery, G.C. Anderson, P.J. Dolling, F.X. Dunin, and B.A. Keating. 1998a. Use of the APSIM wheat model to predict yield, drainage, and $\mathrm{NO}_{3}{ }^{-}$leaching for a deep sand. Aust. J. Agric. Res. 49:363-377. doi:10.1071/A97095

Asseng, S., I. Foster, and N.C. Turner. 2011. The impact of temperature variability on wheat yields. Global Change Biol. 17:997-1012. doi:10.1111/j.1365-2486.2010.02262.x

Asseng, S., B.A. Keating, I.R.P. Fillery, P.J. Gregory, J.W. Bowden, N.C. Turner, et al. 1998. Performance of the APSIM-wheat model in Western Australia. Field Crops Res. 57:163-179. doi:10.1016/S0378-4290(97)00117-2

Chen, C., W.E. Baethgen, and A. Robertson. 2012. Contributions of individual variation in temperature, solar radiation and precipitation to crop yield in the North China Plain, 1961-2003. Clim. Change 116:767-788.

Chen, C., E. Wang, and Q. Yu. 2010a. Modeling wheat and maize productivity as affected by climate variation and irrigation supply in North China Plain. Agron. J. 102:1037-1049. doi:10.2134/agronj2009.0505

Chen, C., E. Wang, and Q.A. Yu. 2010b. Modelling the effects of climate variability and water management on crop water productivity and water balance in the North China Plain. Agric. Water Manage. 97:1175-1184. doi:10.1016/j.agwat.2008.11.012

Chen, C., E. Wang, Q. Yu, and Y. Zhang. 2010c. Quantifying the effects of climate trends in the past 43 years (1961-2003) on crop growth and water demand in the North China Plain. Clim. Change 100:559-578. doi:10.1007/s10584-009-9690-3 
Cooper, P., J. Dimes, K. Rao, B. Shapiro, B. Shiferaw, and S. Twomlow. 2008. Coping better with current climatic variability in the rainfed farming systems of sub-Saharan Africa: An essential first step in adapting to future climate change? Agric. Ecosyst. Environ. 126:24-35. doi:10.1016/j.agee.2008.01.007

Deng, X.P., L. Shan, H.P. Zhang, and N.C. Turner. 2006. Improving agricultural water use efficiency in arid and semiarid areas of China. Agric. Water Manage. 80:23-40. doi:10.1016/j.agwat.2005.07.021

Doherty, A., V. Sadras, D. Rodriguez, and A. Potgieter. 2010. Quantification of wheat water-use efficiency at the shire-level in Australia. Crop Pasture Sci. 61:1-11. doi:10.1071/CP09157

Gholipoor, M. 2012. Simulation study of past survival trends in over-wintering of wheat in Iran. Int. J. Plant Prod. 6:149-160.

Guan, F., Y. Zheng, Z. Cai, C. Yu, and N. Zhang. 2011. Study of distinctive regional features of surface solar radiation in North and East China. Acta Meteorol. Sin. 25:494-505. doi:10.1007/s13351-011-0408-x

Intergovernmental Panel on Climate Change. 2007. Climate change 2007: Synthesis report. Contribution of Working Groups I, II and III to the Fourth Assessment Report of the Intergovernmental Panel on Climate Change. IPCC, Geneva, Switzerland.

Keating, B.A., P.S. Carberry, G.L. Hammer, M.E. Probert, M.J. Robertson, D. Holzworth, et al. 2003. An overview of APSIM, a model designed for farming systems simulation. Eur. J. Agron. 18:267-288. doi:10.1016/ S1161-0301(02)00108-9

Li, Z., W.-Z. Liu, X.-C. Zhang, and F.-L. Zheng. 2011. Assessing the site-specific impacts of climate change on hydrology, soil erosion and crop yields in the Loess Plateau of China. Clim. Change 105:223-242. doi:10.1007/ s10584-010-9875-9

Li, Z.C., Z.G. Wei, J. Wen, and R. Fu. 2008. Analyses on climate variation characteristics over the Loess Plateau in recent 50 years. (In Chinese, with English abstract.) J. Arid Land Resour. Environ. 22:57-62.

Liu, Y., E. Wang, X. Yang, and J. Wang. 2010. Contributions of climatic and crop varietal changes to crop production in the North China Plain, since 1980s. Global Change Biol. 16:2287-2299. doi:10.1111/j.1365-2486.2009.02077.x

Lobell, D.B., and G.P. Asner. 2003. Climate and management contributions to recent trends in U.S. agricultural yields. Science 299:1032. doi:10.1126/ science. 1077838

Lobell, D.B., and M.B. Burke. 2010. On the use of statistical models to predict crop yield responses to climate change. Agric. For. Meteorol. 150:14431452. doi:10.1016/j.agrformet.2010.07.008

McCown, R.L., G.L. Hammer, J.N.G. Hargreaves, D.P. Holzworth, and D.M. Freebairn. 1996. APSIM: A novel software system for model development, model testing and simulation in agricultural systems research. Agric. Syst. 50:255-271. doi:10.1016/0308-521X(94)00055-V

Nicholls, N. 1997. Increased Australian wheat yield due to recent climate trends. Nature 387:484-485. doi:10.1038/387484a0

Peng, S.B., J.L. Huang, J.E. Sheehy, R.C. Laza, R.M. Visperas, X.H. Zhong, et al. 2004. Rice yields decline with higher night temperature from global warming. Proc. Natl. Acad. Sci. 101:9971-9975. doi:10.1073/ pnas.0403720101

Piao, S., P. Ciais, Y. Huang, Z. Shen, S. Peng, J. Li, et al. 2010. The impacts of climate change on water resources and agriculture in China. Nature 467:43-51. doi:10.1038/nature09364

Prescott, J. 1940. Evaporation from a water surface in relation to solar radiation. Trans. R. Soc. South Aust. 64:114-125.

Probert, M.E., B.A. Keating, J.P. Thompson, and W.J. Parton. 1995. Modelling water, nitrogen, and crop yield for a long-term fallow management experiment. Aust. J. Exp. Agric. 35:941-950. doi:10.1071/EA9950941

Reyenga, P.J., S.M. Howden, H. Meinke, and W.B. Hall. 2001. Global change impacts on wheat production along an environmental gradient in South Australia. Environ. Int. 27:195-200. doi:10.1016/ S0160-4120(01)00082-4

Rockstrom, J., L. Karlberg, S.P. Wani, J. Barron, N. Hatibu, T. Oweis, et al. 2010. Managing water in rainfed agriculture: The need for a paradigm shift. Agric. Water Manage. 97:543-550. doi:10.1016/j. agwat.2009.09.009
Seber, G.A.F. 2008. Cluster analysis. In: Multivariate observations. John Wiley \& Sons, Hoboken, NJ. p. 347-394. doi:10.1002/9780470316641.ch7

Stanhill, G., and S. Cohen. 2001. Global dimming: A review of the evidence for a widespread and significant reduction in global radiation with discussion of its probable causes and possible agricultural consequences. Agric. For. Meteorol. 107:255-278. doi:10.1016/S0168-1923(00)00241-0

Sun, J., X. Zou, Q. Gao, B. Jia, and X. Yang. 2010. Natural background of China's drylands. In: L. Ci and X. Yang, editors, Desertification and its control in China. Springer, Berlin. p. 29-99.

Tao, F., M. Yokozawa, Y. Xu, Y. Hayashi, and Z. Zhang. 2006. Climate changes and trends in phenology and yields of field crops in China, 1981-2000. Agric. For. Meteorol. 138:82-92. doi:10.1016/j.agrformet.2006.03.014

Turner, N.C., N. Molyneux, S. Yang, Y.-C. Xiong, and K.H.M. Siddique. 2011. Climate change in south-west Australia and north-west China: Challenges and opportunities for crop production. Crop Pasture Sci. 62:445-456. doi:10.1071/CP10372

Wang, E.L., C.J. Smith, W.J. Bond, and K. Verburg. 2004. Estimations of vapour pressure deficit and crop water demand in APSIM and their implications for prediction of crop yield, water use, and deep drainage. Aust. J. Agric. Res. 55:1227-1240. doi:10.1071/AR03216

Wang, H.L., Y.T. Gan, R.Y. Wang, J.Y. Niu, H. Zhao, Q.G. Yang, and G.C. Li. 2008. Phenological trends in winter wheat and spring cotton in response to climate changes in northwest China. Agric. For. Meteorol. 148:12421251. doi:10.1016/j.agrformet.2008.03.003

Wang, Q., X. Fan, Z. Qin, and M. Wang. 2012. Change trends of temperature and precipitation in the Loess Plateau region of China, 1961-2010. Global Planet. Change 92-93:138-147. doi:10.1016/j.gloplacha.2012.05.010

Wang, X.C., and J. Li. 2010. Evaluation of crop yield and soil water estimates using the EPIC model for the Loess Plateau of China. Math. Comput. Model. 51:1390-1397. doi:10.1016/j.mcm.2009.10.030

Wang, X.C., J. Li, M.N. Tahir, and M.D. Hao. 2011. Validation of the EPIC model using a long-term experimental data on the semi-arid Loess Plateau of China. Math. Comput. Model. 54:976-986. doi:10.1016/j. mcm.2010.11.025

Willmott, C.J., S.G. Ackleson, R.E. Davis, J.J. Feddema, K.M. Klink, D.R. Legates, et al. 1985. Statistics for the evaluation and comparison of models. J. Geophys. Res. 90:8995-9005. doi:10.1029/ JC090iC05p08995

Xiao, G., Q. Zhang, Y. Li, R. Wang, Y. Yao, H. Zhao, and H. Bai. 2010. Impact of temperature increase on the yield of winter wheat at low and high altitudes in semiarid northwestern China. Agric. Water Manage. 97:1360-1364. doi:10.1016/j.agwat.2010.04.002

Xin, Z., X. Yu, Q. Li, and X. Lu. 2011. Spatiotemporal variation in rainfall erosivity on the Chinese Loess Plateau during the period 1956-2008. Reg. Environ. Change 11:149-159. doi:10.1007/s10113-010-0127-3

Yang, X., C. Chen, Q. Luo, L. Li, and Q. Yu. 2011. Climate change effects on wheat yield and water use in oasis cropland. Int. J. Plant Prod. 5:83-94.

Yu, Q., H. Hengsdijk, and J.D. Liu. 2001. Application of a progressivedifference method to identify climatic factors causing variation in the rice yield in the Yangtze Delta, China. Int. J. Biometeorol. 45:53-58. doi:10.1007/s004840000084

Yu, Q., L. Li, Q. Luo, D. Eamus, S. Xu, C. Chen, et al. 2014. Year patterns of climate impact on wheat yields. Int. J. Climatol. 34:518-528. doi:10.1002/joc.3704

Yu, Q., S.A. Saseendran, L. Ma, G.N. Flerchinger, T.R. Green, and L.R. Ahuja. 2006. Modeling a wheat-maize double cropping system in China using two plant growth modules in RZWQM. Agric. Syst. 89:457-477. doi:10.1016/j.agsy.2005.10.009

Zhang, X.-C., and W.-Z. Liu. 2005. Simulating potential response of hydrology, soil erosion, and crop productivity to climate change in Changwu tableland region on the Loess Plateau of China. Agric. For. Meteorol. 131: 127-142. doi:10.1016/j.agrformet.2005.05.005 